\title{
Perspective and future direction of intraventricular mechanical dyssynchrony assessment
}

\author{
Guillermo Romero-Farina, MD, PhD, FESC, FASNC, ${ }^{\text {a,b }}$ \\ and Santiago Aguadé-Bruix, $M D^{b}$ \\ a Cardiology Department, Hospital Universitari Vall d'Hebron, Institut de Recerca (VHIR), \\ Universitat Autònoma de Barcelona, Barcelona, Spain \\ b Department of Nuclear Medicine, Hospital Universitari Vall d'Hebron, Institut de Recerca \\ (VHIR), Universitat Autònoma de Barcelona, Barcelona, Spain
}

Received Jan 8, 2019; accepted Jan 8, 2019

doi: $10.1007 / \mathrm{s} 12350-019-01604-3$

See related article, pp. 55-64

This editorial refers to the article published by Peix et al. ${ }^{1}$ titled 'Value of intraventricular dyssynchrony assessment by gated-SPECT myocardial perfusion imaging in the management of heart failure patients undergoing cardiac resynchronization therapy (VISION$C R T)^{\prime}$ on the Journal of Nuclear Cardiology.

This study shows the importance of the current problem in cardiac resynchronization therapy (CRT). In this study, we observe multiple variables that can affect the CRT response in clinical practice ${ }^{2}$ : patients with or without previous myocardial infarction, patients in ischemic cardiomyopathy phase, patients with or without myocardial ischemia, patients with or without coronary revascularization before gated SPECT study, patients with complete or incomplete revascularization, patients with or without myocardial viability criteria, patients with different large infarct size, patients with or without medical treatment optimizations during the follow-up, the cut-off value to define significant dyssynchrony, responder and non-responder patients, on-target group patients and off-target group patients, acquisition of images with different frames ( 8 or 16

\footnotetext{
Reprint requests: Guillermo Romero-Farina, MD, PhD, FESC, FASNC, Cardiology Department, Hospital Universitari Vall d'Hebron, Institut de Recerca (VHIR), Universitat Autònoma de Barcelona, Paseo Vall d'Hebron 119-129, 08035 Barcelona, Spain; guiromfar@gmail.com

J Nucl Cardiol 2021;28:65-71.

$1071-3581 / \$ 34.00$

Copyright (c) 2019 American Society of Nuclear Cardiology.
}

frames), and different algorithms to guide left ventricular (LV) lead position placement, and the selected variables for the multivariate analysis.

The importance of perspective and the future direction of intraventricular dyssynchrony assessment lies in the multiple variables that must be taken into account, and the fact that the heart failure (HF) represents a rapidly growing epidemic. ${ }^{3}$ Approximately 5.8 million patients in the United States currently suffer from HF, and over 670,000 of them are newly diagnosed with HF each year. ${ }^{3}$ Currently, the prediction is that in the United States by 2035, > 9 million will have $\mathrm{HF}^{4}$; the 5-year mortality after a diagnosis of HF is approximately $50 \%$. Also, in United Kingdom, Conrad et al. ${ }^{5}$ observed that from 2002 to 2014, HF incidence decreased, similarly for men and women. However, the estimated absolute number of individuals with newly diagnosed HF in the UK increased by $12 \%$ (from 170727 in 2002 to 190798 in 2014), largely due to an increase in population size and age. The estimated absolute number of prevalent HF cases in the UK increased even more, by 23\% (from 750127 to 920616).

The most important issue to be resolved in the future is, how to improve the criteria for cardiac resynchronization therapy (CRT)? Recently, Lyons et al. ${ }^{6}$ identified 25,102 hospitalizations for HF that included patients with a LV ejection fraction (LVEF) $\leq 35 \%$ from 283 hospitals. Observed, that $49.1 \%$ ( $\mathrm{n}=12,336)$ of patients with HF, an LVEF $\leq 35 \%$, and no documented contraindication were eligible for CRT on the basis of historical guidelines (LVEF $\leq 35 \%$, QRS duration $\geq 120 \mathrm{~ms}$, and NYHA functional class III or IV) ${ }^{7}$ and $33.1 \%(n=8299)$ of patients were eligible for CRT on the basis of current guidelines (LVEF $\leq 35 \%$, left bundle branch block [LBBB] with a QRS duration 
$\geq 120 \mathrm{~ms}$ or non-LBBB (right bundle branch block or interventricular conduction delay) with a QRS duration $\geq 150 \mathrm{~ms}$ and NYHA functional class II, III, or IV). ${ }^{8}$ Concluded that, in this population of patients with HF, an LVEF $\leq 35 \%$, and no documented contraindication for CRT, the current ACCF/AHA HF guidelines reduce the proportion of patients eligible for CRT by approximately $15 \% .^{6}$

Currently, all the information provided in relation to $\mathrm{CRT}^{1-37}$ and the experience in the clinical practice site of patients with HF, suggests that probably the criteria for CRT should be considered again. If a patient with HF and severely depressed LVEF does not respond to pharmacological treatment, CRT should be considered (Figure 1-1st); before the appearance of a branch block or an increase in the duration of the QRS complex. ${ }^{9,10}$ Why? because there may be ventricular mechanical dyssynchrony without branch block with normal $\mathrm{QRS}^{9}$ (Figure 2); and although electrical and mechanical dyssynchrony often coincide, electrical and mechanical dyssynchrony are commonly not present at the same time in a given patient. ${ }^{10}$ LBBB is not always accompanied by mechanical dyssynchrony. ${ }^{11}$ Moreover, the percentage of non-responder patients remains high and heterogeneous $(20 \%-40 \%) .{ }^{10,12}$

Another aspect little studied is the relationship between the contractile reserve (Figure 1-2nd) prior to the CRT and responder and non-responder patients. ${ }^{13,14}$ The correct thing would be to study the contractile reserve prior to CRT. ${ }^{16}$ Kloosterman et al. ${ }^{17}$ observed that, a cardiac muscle without or poor contractile response will not have an effective response to CRT (the positive association between contractile reserve and CRT response remained with an odds ratio of 2.42 (95\% CI $1.17-5.05, P=0.018) .{ }^{17}$ Also, the U-shaped contraction pattern is associated with improved CRT response. ${ }^{14}$ In addiction, myocardial fibrosis is associated with a worse response to CRT, particularly if it is sizable, transmural, or located in posterolateral left ventricular segments where the LV lead is usually positioned. ${ }^{37}$

The degree of mechanical dyssynchrony (Figure 13rd) is important to select patients for CRT. ${ }^{18-20}$ We can define the degree according to the number of altered phase parameters (one, two, three, or four: $\mathrm{SD}>18.4^{\circ}$, $\mathrm{B}>51^{\circ}, \mathrm{S} \leq 3.2^{\circ}$, and $\mathrm{K} \leq 9.3^{\circ} 20$ or according to bandwidth degree. Ninety-two percent of patients with criteria for cardiac resynchronization therapy have 3 or 4 abnormal parameters in the phase analysis. ${ }^{20}$

If we think about ventricular mechanical resynchronization, we cannot forget the right ventricle (RV) (Figure 1-4th). We cannot separate LV function and RV function, since there is an interdependent relationship; dilatation of the RV shifts the interventricular septum
Figure 1. Possible and different steps to consider in the future for the indication of CRT in patients with heart failure. $c R V S U V$, correct right ventricular standard uptake value; $F C$, functional class; $L V E F$, left ventricular ejection fraction; NYHA, New York Heart Association; PAP, pulmonary artery pressure; $R V S P$, right ventricular systolic pressure; $R V E F$, right ventricular ejection fraction; $R V F A C$, right ventricular fractional area change. RVFAC is an echocardiographic parameter, but in Nuclear Cardiology Unit, gated pool SPECT is a good technique for the evaluation of right ventricular volume and function. ${ }^{34}$ In the seventh step of this possible algorithm, the presence of LBBB would help to select the best technique for CRT. It should be noted that each step in addition to being related to ventricular dyssynchrony is related to cardiac mortality.

toward the left, changing LV geometry. ${ }^{21} \mathrm{RV}$ dysfunction is an important predictor of survival and exercise capacity in cardiopulmonary disease, and RV failure is a progressive disorder that starts with an initial myocardial injury or stress. ${ }^{21}$ In some patients with chronic HF (Figure 3), the disease process not only impairs cardiac contractility but also causes a delay in the onset of RV or LV systole by affecting the conduction pathways. ${ }^{8}$ Despite this information, RV function is not taken into account in the latest ventricular resynchronization guidelines. For example, in CRT patients with non-ischemic dilated cardiomyopathy and impaired baseline RV function, at mid-term follow-up (3 months), an improvement in RVEF and RV dyssynchrony is noted. ${ }^{22}$ Besides that, van Everdingen et al. ${ }^{23}$ observed that the mechanical dyssynchrony parameters do not reflect the negative impact of reduced RV contractility on CRT response, and commonly used mechanical dyssynchrony parameters are not associated with CRT response when $\mathrm{RV}$ dysfunction ( $\mathrm{RV}$ fractional area change $<35 \%$ ) is present. Thus the prediction of CRT response should therefore include parameters of mechanical dyssynchrony and RV function. ${ }^{23}$ Also, RV dysfunction is associated with an increase in RV FDG uptake (Figure 1-5th), the magnitude of which may be correlated with severity. ${ }^{24}$ Increased RV FDG uptake is associated with RV dysfunction (Figure 3) and may be a prognostic predictor of all-cause mortality or heart transplantation in patients with dilated cardiomyopathy. ${ }^{25}$ There is a significant correlation between RVEF and RV FDG uptake; in patients with a cRVSUV (correct RV standard uptake value) $>7.01$, heart transplantation is more frequent. Furthermore, there is a good correlation between RV dysfunction, RV FDG uptake, and severe pulmonary hypertension (mean pulmonary artery pressure $\geq 40$ 


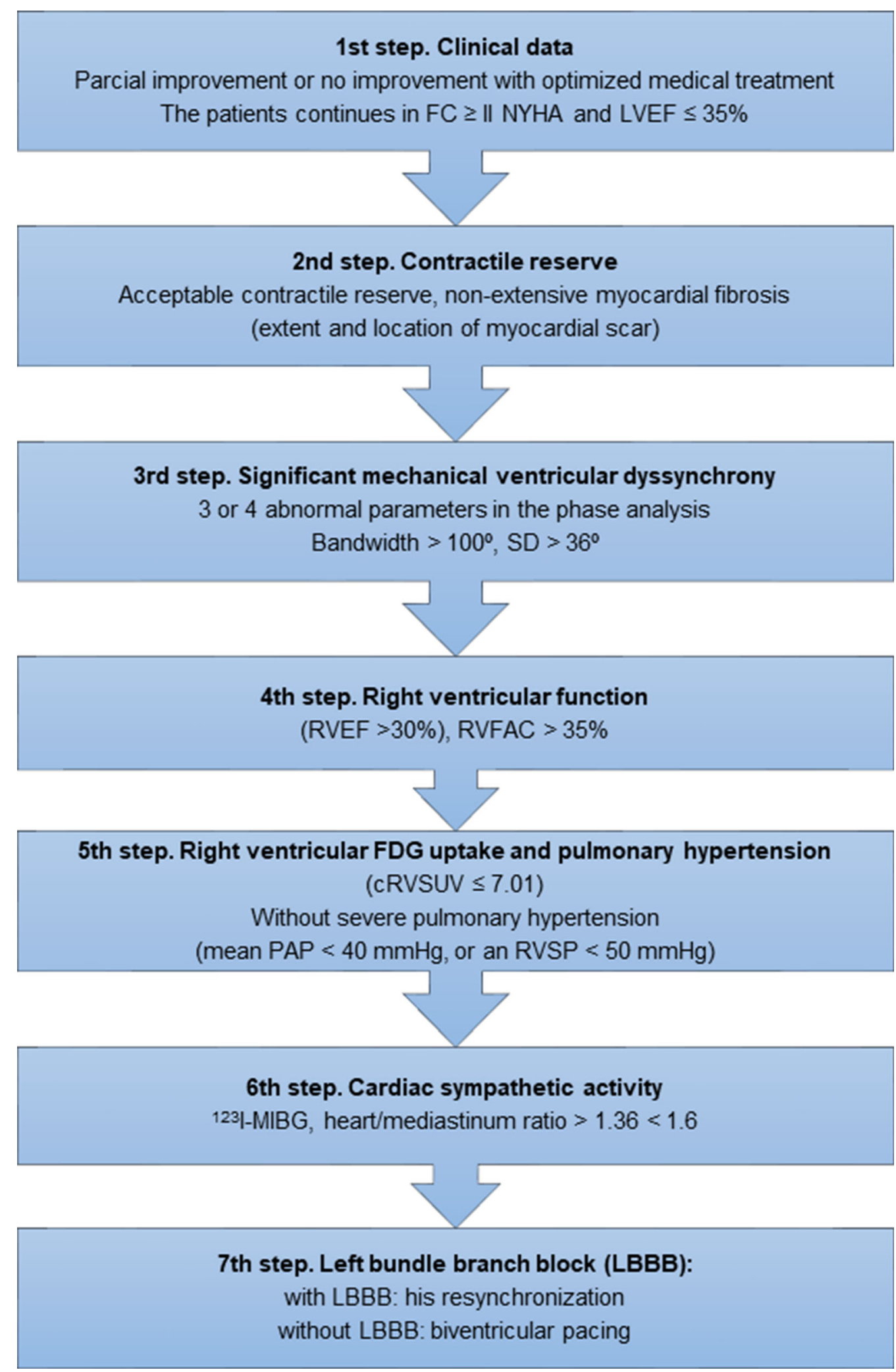




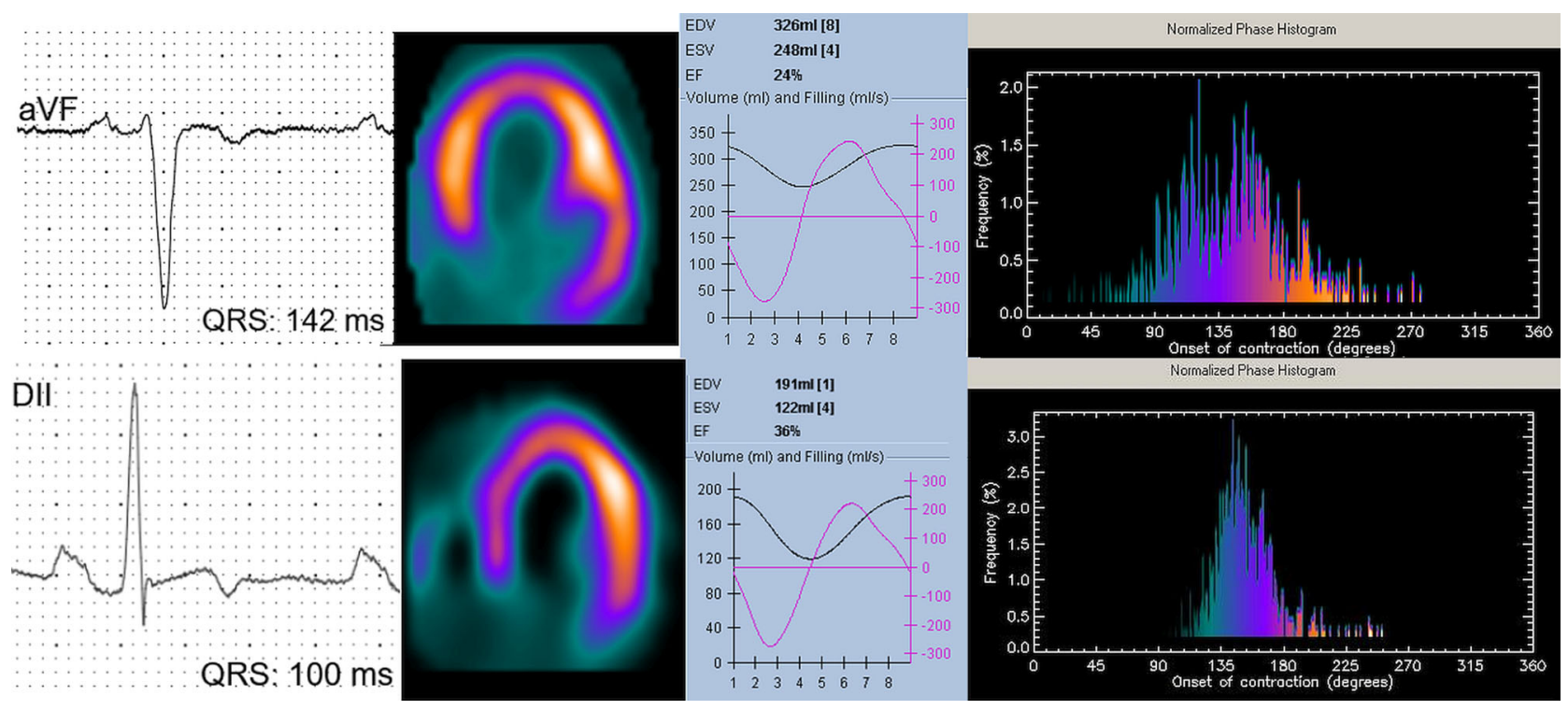

Figure 2. The above case corresponds to a patient with heart failure, with wide QRS and ventricular dyssynchrony (Histogram Bandwidth HB:126, Standard Deviation SD: 39.9), and the case below corresponds to a patient with heart failure, with normal QRS, and ventricular dyssynchrony (HB: 67, SD: 21.4). EDV, end-diastolic volume; $E F$, ejection fraction; $E S V$, endsystolic volume.

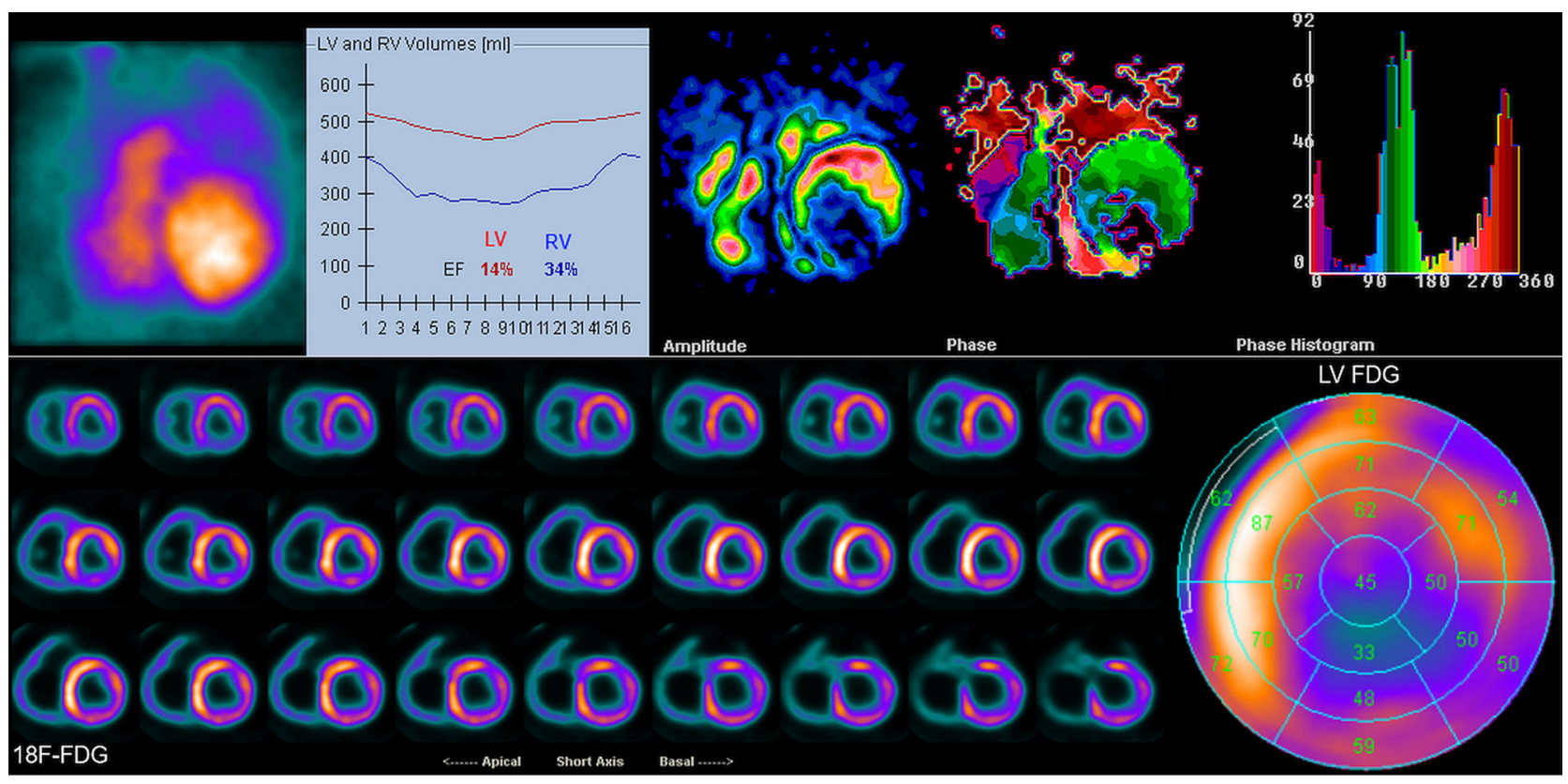

Figure 3. At the top (equilibrium radionuclide ventriculography images) of the figure, marked dyssynchrony between the right (RV) and left ventricle (LV) is observed. At the bottom of the figure, RV dilatation and dysfunction are associated with an increase in RV PET ${ }^{18} \mathrm{~F}$-FDG uptake. $E F$, ejection fraction.

$\mathrm{mmHg}$, or an RV systolic pressure $\geq 50 \mathrm{mmHg}$ ); and severe pulmonary hypertension has a poor prognosis. ${ }^{24,25}$ Thus, RV performance in patients of pulmonary hypertension requires optimal assessment; and RV dyssynchrony measured by phase analysis of FDG-PET is significantly related to RV dysfunction. ${ }^{26}$ 

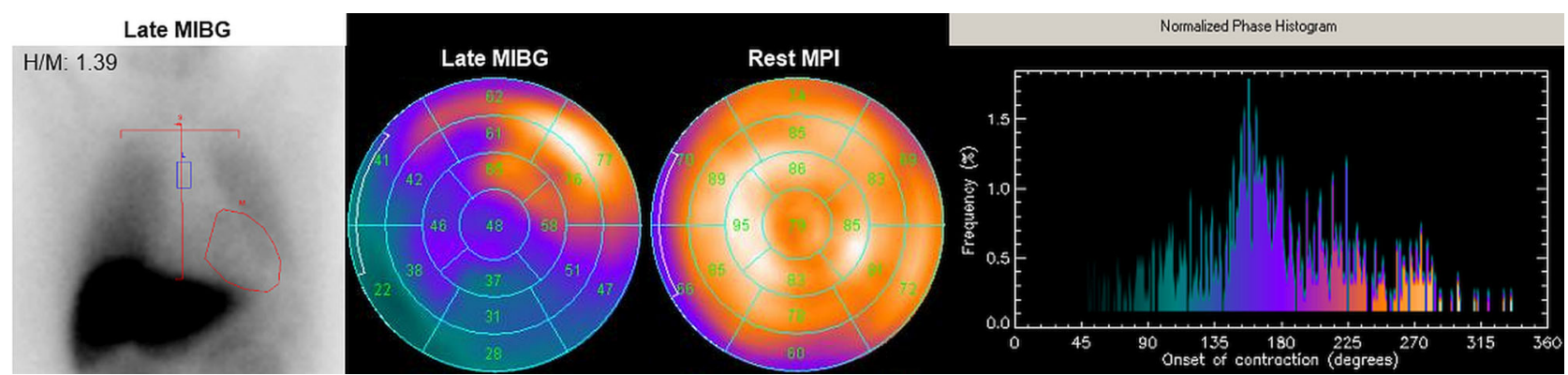

Figure 4. In this case, a relationship between regional sympathetic denervation with H/M (heart/mediastinum) ratio 1.39, mismatch innervation/perfusion, and left ventricular dyssynchrony is observed (Histogram Bandwidth HB 191, Standard Deviation SD 53.5). MIBG, ${ }^{123} \mathrm{I}-$ metaiodobenzylguanidine.

The evaluation of LV sympathetic innervation on ${ }^{123}$ I-metaiodobenzylguanidine (123I-MIBG) imaging (Figure 1-6th) is another useful tool to assess CRT. ${ }^{27-29}$ Gimelli et al. ${ }^{28}$ observed that patients with LV dyssynchrony show an extensive burden "innervation/ perfusion" mismatch that is concentrated at the level of the dyssynchronous LV walls, suggesting a relationship between regional sympathetic denervation and abnormal LV mechanics (Figure 4). The optimal heart/mediastinum uptake ratio cut-off point is between 1.36 (sensitivity, $75 \%$; specificity, $71 \%$ ) and $<1.6$ to CRT response. $^{30,31}$

The presence of branch block (Figure 1-7th) is probably more important to define the type of CRT, rather than the indication for CRT. ${ }^{32,33}$ Recently, Arnold et al. ${ }^{32}$ analyzed patients with HF and LBBB referred for conventional biventricular CRT, and concluded that His resynchronization delivers better ventricular resynchronization, and greater improvement in hemodynamic parameters, than biventricular pacing.

In conclusion, the perspective and future direction of intraventricular mechanical dyssynchrony assessment should consider all these aspects in HF patients (Figure 2), and not focus solely on the LBBB and QRS duration to select the best candidates for an effective CRT because electrical and mechanical dyssynchrony are not interchangeable. ${ }^{35}$ Prior to CRT, it is important to consider jointly, the assessment of right and left ventricular systolic function, the myocardial scar areas, the degree of mechanical dyssynchrony, the cardiac sympathetic activity, and the pulmonary artery pressure; and probably use the LBBB to choose the best resynchronization technique for each individual patient; in order to reduce the high rate of non-responder patients. In addition, the presence of mechanical dyssynchrony predicted long-term outcome better than guideline Classes I, IIa, IIb. ${ }^{36}$

\section{Disclosures}

The authors report no potential conflict of interest relevant to this editorial.

\section{References}

1. Peix A, Karthikeyan G, Massardo T, Kalaivani M, Patel Ch, Pabon $\mathrm{L}$, et al. Value of intraventricular dyssynchrony assessment by gated-SPECT myocardial perfusion imaging in the management of heart failure patients undergoing cardiac resynchronization therapy (VISION-CRT). J Nucl Cardiol 2019.

2. Romero-Farina G, Aguadé-Bruix S. Analysis of ventricular synchrony: A complex puzzle. J Nucl Cardiol. 2018. https://doi.org/ 10.1007/s12350-018-1208-9.

3. Patel MR, White RD, Abbara S, Bluemke DA, Herfkens RJ, Picard M, et al. American College of Radiology Appropriateness Criteria Committee; American College of Cardiology Foundation Appropriate Use Criteria Task Force. ACCF/ACR/ASE/ASNC/ SCCT/SCMR appropriate utilization of cardiovascular imaging in heart failure: a joint report of the American College of Radiology Appropriateness Criteria Committee and the American College of Cardiology Foundation Appropriate Use Criteria Task Force. J Am Coll Cardiol. 2013;61:2207-31.

4. Iskandrian $\mathrm{AE}$. The future of nuclear cardiac imaging: Reflection and a vision. J Nucl Cardiol. 2018;25:1-5.

5. Conrad N, Judge A, Tran J, Mohseni H, Hedgecott D, Crespillo AP, et al. Temporal trends and patterns in heart failure incidence: a population-based study of 4 million individuals. Lancet. 2018;391:572-80.

6. Lyons KJ, Ezekowitz JA, Liang L, Heidenreich PA, Yancy CW, DeVore $\mathrm{AD}$, et al. Impact of current versus previous cardiac resynchronization therapy guidelines on the proportion of patients with heart failure eligible for therapy. JACC Heart Fail. 2017;5:388-92. 
7. Jessup M, Abraham WT, Casey DE, Feldman AM, Francis GS, Ganiats TG, et al. 2009 focused update: ACCF/AHA guidelines for the diagnosis and management of heart failure in adults: a report of the American College of Cardiology Foundation/American Heart Association Task Force on Practice Guidelines: developed in collaboration with the International Society for Heart and Lung Transplantation. J Am Coll Cardiol. 2009;53:1343-82.

8. Yancy CW, Jessup M, Bozkurt B, Butler J, Casey DE Jr, Drazner $\mathrm{MH}$, et al. 2013 ACCF/AHA guideline for the management of heart failure. J Am Coll Cardiol. 2013;62:e147-239.

9. Benz DC, Pazhenkottil AP. Cardiac resynchronization therapy in chronic heart failure: Effect on right ventricular function. J Nucl Cardiol. 2017. https://doi.org/10.1007/s12350-017-0953-5.

10. Fudim M, Borges-Neto S. A troubled marriage: When electrical and mechanical dyssynchrony don't go along. J Nucl Cardiol. 2018. https://doi.org/10.1007/s12350-018-1227-6.

11. Sillanmäki S, Lipponen JA, Tarvainen MP, Laitinen T, Hedman M, Hedman A, et al. Relationships between electrical and mechanical dyssynchrony in patients with left bundle branch block and healthy controls. J Nucl Cardiol. 2018. https://doi.org/10.100 7/s12350-018-1204-0.

12. Bertini M, Höke U, van Bommel RJ, Ng AC, Shanks M, Nucifora $\mathrm{G}$, et al. Impact of clinical and echocardiographic response to cardiac resynchronization therapy on long-term survival. Eur Heart J Cardiovasc Imaging. 2013;14:774-81.

13. Legallois D, Marie PY, Franken PR, Djaballah W, Agostini D, Manrique A. Comparison of the dyssynchrony parameters recorded with gated SPECT in ischemic cardiomyopathy according to their repeatability at rest and to their ability to detect a synchrony reserve under dobutamine infusion. J Nucl Cardiol. 2018. https://d oi.org/10.1007/s12350-018-01546-2.

14. Tao N, Qiu Y, Tang H, Qian Z, Wu H, Zhu R, et al. Assessment of left ventricular contraction patterns using gated SPECT MPI to predict cardiac resynchronization therapy response. J Nucl Cardiol. 2018;25:2029-38.

15. Verna E, Ghiringhelli S, Scotti S, Caravati F. Evaluation of baseline contractile reserve vs dyssynchrony as a predictor of functional improvement and long term outcome after resynchronization pacing therapy: a radionuclide stress study. J Nucl Cardiol. 2012;19:53-62.

16. AlJaroudi W, Alraies MC, Menon V, Brunken RC, Cerqueira MD, Jaber WA. Predictors and incremental prognostic value of left ventricular mechanical dyssynchrony response during stress-gated positron emission tomography in patients with ischemic cardiomyopathy. J Nucl Cardiol. 2012;19:958-69.

17. Kloosterman M, Damman K, Van Veldhuisen DJ, Rienstra M, Maass AH. The importance of myocardial contractile reserve in predicting response to cardiac resynchronization therapy. Eur J Heart Fail. 2017;19:862-9.

18. Romero-Farina G, Aguadé-Bruix S, Candell-Riera J, Pizzi MN, García-Dorado D. Cut-off values of myocardial perfusion gatedSPECT phase analysis parameters of normal subjects, and conduction and mechanical cardiac diseases. J Nucl Cardiol. 2015;22:1247-58.

19. Zafrir N. Left ventricular mechanical dyssynchrony graduation of myocardial perfusion gated SPECT phase analysis: What next. J Nucl Cardiol. 2018;25:1009-11.

20. Aguadé-Bruix S, Romero-Farina G, Candell-Riera J, Pizzi MN, García-Dorado D. Mechanical dyssynchrony according to validated cut-off values using gated SPECT myocardial perfusion imaging. J Nucl Cardiol. 2018;25:999-1008.

21. Haddad F, Doyle R, Murphy DJ, Hunt SA. Right ventricular function in cardiovascular disease, part II: pathophysiology, clinical importance, and management of right ventricular failure. Circulation. 2008;117:1717-31.

22. Valzania C, Biffi M, Bonfiglioli R, Fallani F, Martignani C, Diemberger I, et al. Effects of cardiac resynchronization therapy on right ventricular function during rest and exercise, as assessed by radionuclide angiography, and on NT-proBNP levels. J Nucl Cardiol. 2017. https://doi.org/10.1007/s12350-017-0971-3.

23. van Everdingen WM, Walmsley J, Cramer MJ, van Hagen I, De Boeck BWL, Meine M, et al. Echocardiographic prediction of cardiac resynchronization therapy response requires analysis of both mechanical dyssynchrony and right ventricular function: A combined analysis of patient data and computer simulations. J Am Soc Echocardiogr. 2017;30:1012-20.

24. Mielniczuk LM, Birnie D, Ziadi MC, deKemp RA, DaSilva JN, Burwash I, et al. Relation between right ventricular function and increased right ventricular $[18 \mathrm{~F}]$ fluorodeoxyglucose accumulation in patients with heart failure. Circ Cardiovasc Imaging. 2011;4:59-66.

25. Wang L, Ma X, Xiang L, Lu M, Yan C, Zhao S, et al. The characterization and prognostic significance of right ventricular glucose metabolism in non-ischemic dilated cardiomyopathy. J Nucl Cardiol. 2016;23:758-67.

26. Wang L, Zhou W, Liang Y, Yang Y, Garcia EV, Chen J, et al. Right ventricular dyssynchrony in pulmonary hypertension: Phase analysis using FDG-PET imaging. J Nucl Cardiol. 2017;24:69-78.

27. Nakajima K, Okuda K, Verberne HJ. Phase dyssynchrony and (123)I-meta-iodobenzylguanidine innervation imaging towards standardization. J Nucl Cardiol. 2017. https://doi.org/10.1007/s12 350-017-0971-3.

28. Gimelli A, Liga R, Menichetti F, Soldati E, Bongiorni MG, Marzullo P. Interactions between myocardial sympathetic denervation and left ventricular mechanical dyssynchrony: A CZT analysis. J Nucl Cardiol. 2017. https://doi.org/10.1007/s12350-01 7-1036-3.

29. Moreira RI, Abreu A, Portugal G, Oliveira L, Oliveira M, Rodrigues I, et al. Prognostic effect and modulation of cardiac sympathetic function in heart failure patients treated with cardiac resynchronization therapy. J Nucl Cardiol. 2018. https://doi.org/ 10.1007/s12350-018-1357-x.

30. Nishioka SA, Martinelli Filho M, Brandão SC, Giorgi MC, Vieira ML, Costa R, et al. Cardiac sympathetic activity pre and post resynchronization therapy evaluated by 123I-MIBG myocardial scintigraphy. J Nucl Cardiol. 2007;14:852-9.

31. Jacobson AF, Senior R, Cerqueira MD, Wong ND, Thomas GS, Lopez VA, et al. ADMIRE-HF Investigators. Myocardial iodine123 meta-iodobenzylguanidine imaging and cardiac events in heart failure. Results of the prospective ADMIRE-HF (AdreView Myocardial Imaging for Risk Evaluation in Heart Failure) study. J Am Coll Cardiol. 2010;55:2212-21.

32. Arnold AD, Shun-Shin MJ, Keene D, Howard JP, Sohaib SMA, Wright IJ, et al. His resynchronization versus biventricular pacing in patients with heart failure and left bundle branch block. J Am Coll Cardiol. 2018;72:3112-22.

33. Lustgarten DL, Crespo EM, Arkhipova-Jenkins I, Lobel R, Winget $\mathrm{J}$, Koehler J, et al. His-bundle pacing versus biventricular pacing in cardiac resynchronization therapy patients: A crossover design comparison. Heart Rhythm. 2015;12:1548-57.

34. Dercle L, Ouali M, Pascal P, Giraudmaillet T, Chisin R, Lairez O, et al. Gated blood pool SPECT: The estimation of right ventricular volume and function is algorithm dependent in a clinical setting. $\mathrm{J}$ Nucl Cardiol. 2015;22:483-92.

35. AlJaroudi W. Mechanical dyssynchrony with phase analysis of gated SPECT: Nap time is over. J Nucl Cardiol. 2018;25:2039-43. 
36. Beela AS, Ünlü S, Duchenne J, Ciarka A, Daraban AM, Kotrc M, et al. Assessment of mechanical dyssynchrony can improve the prognostic value of guideline-based patient selection for cardiac resynchronization therapy. Eur Heart $\mathrm{J}$ Cardiovasc Imaging. 2019;20:66-74.

37. Bisson A, Pucheux J, Andre C, Bernard A, Pierre B, Babuty D, et al. Localization of left ventricular lead electrodes in relation to myocardial scar in patients undergoing cardiac resynchronization therapy. J Am Heart Assoc. 2018 Nov 6;7(21):e009502.

Publisher's Note Springer Nature remains neutral with regard to jurisdictional claims in published maps and institutional affiliations. 